\title{
GCU
}

Glasgow Caledonian

University

University for the Common Good

\section{On-line PD detection and localization in cross-bonded HV cable systems}

Sheng, Bojie; Zhou, Wenjun; Yu, Jianhui; Meng, Shaoxin; Zhou, Chengke; Hepburn, Donald M.

Published in:

IEEE Transactions on Dielectrics and Electrical Insulation

DOI:

10.1109/TDEI.2014.004446

Publication date:

2014

Document Version

Author accepted manuscript

Link to publication in ResearchOnline

Citation for published version (Harvard):

Sheng, B, Zhou, W, Yu, J, Meng, S, Zhou, C \& Hepburn, DM 2014, 'On-line PD detection and localization in cross-bonded HV cable systems', IEEE Transactions on Dielectrics and Electrical Insulation, vol. 21, no. 5, pp. 2217-2224. https://doi.org/10.1109/TDEl.2014.004446

\section{General rights}

Copyright and moral rights for the publications made accessible in the public portal are retained by the authors and/or other copyright owners and it is a condition of accessing publications that users recognise and abide by the legal requirements associated with these rights.

Take down policy

If you believe that this document breaches copyright please view our takedown policy at https://edshare.gcu.ac.uk/id/eprint/5179 for details of how to contact us. 


\title{
On-line PD Detection and Localisation in Cross-bonded HV Cable Systems
}

\author{
Bojie Sheng, Wenjun Zhou, Jianhui Yu \\ Wuhan University \\ School of Electrical Engineering \\ Wuhan, 430072, China \\ Zhaoxin Meng \\ EPRI, China State Grid, Wuhan, China \\ Chengke Zhou and Donald M Hepburn \\ Glasgow Caledonian University \\ School of Engineering and Built Environment \\ Glasgow, G4 0BA, UK
}

\begin{abstract}
This paper addresses the detection and localization of partial discharge (PD) in crossbonded (CB) high voltage (HV) cables. A great deal has been published in recent years on PD based cable insulation condition monitoring, diagnostics and localisation in medium voltage (MV) and high voltage (HV) cables. The topic of pulse propagation and PD source localization in CB HV cable systems has yet to be significantly investigated. The main challenge to PD monitoring of $\mathrm{CB} \mathrm{HV}$ cables is as a result of the interconnectedness of the sheaths of the three single phase cables. The cross-bonding of the sheaths makes it difficult to localise which of the three phases a PD signal has emanated from. Co-axial cables are used to connect cable sheaths to cable link boxes, for ease of installation and protection against moisture. A second challenge is, therefore, the coupling effect when a PD pulse propagates in $\mathrm{HV}$ cable joints and the co-axial cables, making PD detection and localisation more complex. The paper presents experimental investigations into $\mathrm{PD}$ pulse coupling between the cable centre conductor and the sheath and the behavior of $P D$ pulse propagation in $\mathrm{CB} \mathrm{HV}$ cables. It proposes a model to describe PD pulse propagation in a CB HV cable system to allow monitoring and localization, and also presents the knowledge rules required for PD localization in CB HV cable systems.

Index Terms - Cable, cross-bonding, partial discharge, on-line insulation condition monitoring, coupling effect, PD localisation.
\end{abstract}

\section{INTRODUCTION}

POWER cables are subject to electrical, thermal, mechanical, and environmental stresses on a constant basis when in service. These stresses, and occasionally problems resulting from inadequate installation and maintenance practices, lead to insulation degradation and/or defects [1] [2]. In many instances the deterioration leads to partial discharge (PD) which exacerbates the degradation of the insulation and shortens the cable life [3]. As detection of incipient faults through PD monitoring allows timely maintenance and replacement of assets to be carried out and unplanned outage to be reduced [4] [5] it is of great importance to industry.

Although a great deal of research on PD based cable insulation monitoring, diagnostics and localisation in medium voltage (MV) and high voltage (HV) cables has been published in recent years, the study of pulse detection and localization in cross-bonded (CB) cable systems has yet to be reported. HV cable systems are usually designed as $\mathrm{CB}$ systems to minimize screen losses and to limit voltage rise. In 3-phase, single core CB cable systems a whole cable circuit is normally divided into major sections each consisting of three minor sections of similar length, see Figure 1. As indicated in Figure 1, a major section of an $110 \mathrm{kV}$ installation in Wuhan, at the section terminations the sheaths of the cable are cross-bonded and at the ends of the major section the sheaths are grounded [6]. The cross-bonding of the sheaths normally occurs within adjacent link-boxes and MV cables are used for connecting cable sheaths to the link-box for ease of installation and protection against moisture. A schematic diagram of a $\mathrm{CB}$ cable system is shown in Figure 1. 


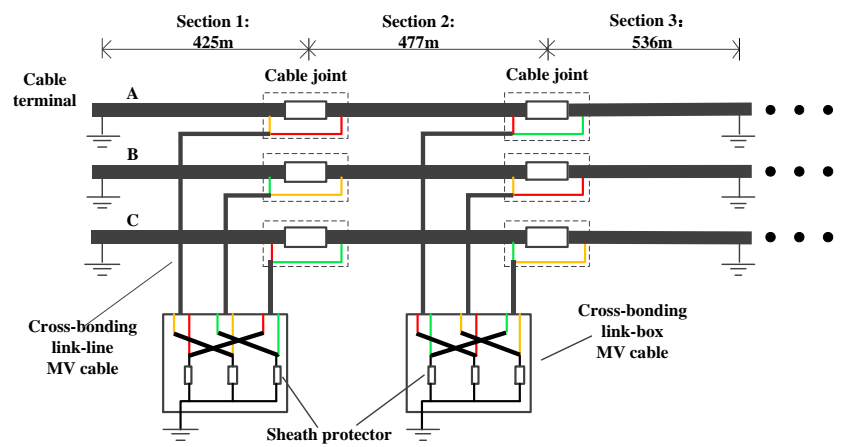

The figures are from a cross-bonding cable system of $110 \mathrm{kV}$ in Wuhan, China: \begin{tabular}{|l|l|l|l|}
\hline Diameter of all the three cable conductors $(\mathrm{m})$ & $38.9^{*} 10^{-3}$ & Relative permittivity of insulation & 2.3 \\
\hline
\end{tabular} \begin{tabular}{|l|c|c|c|c|}
\hline Rated load current flowing in phase A,B,C & 965 & Sheath resistivity coefficient & $2.84^{*} 10^{-8}$ \\
\hline
\end{tabular} \begin{tabular}{|c|c|c|c|}
\hline Distance between phase A and B (m) & 0.27 & External diameter of the sheath $(\mathrm{m})$ & $99.6^{*} 10^{-3}$ \\
\hline
\end{tabular} \begin{tabular}{llllll} 
Distance between phase A and B (m) & 0.27 & Extermal diameter of the sheath $(\mathrm{m})$ & $99.6^{*} 10^{-3}$ \\
\hline Distance between phase B and C (m) & 0.27 & Internal diameter of the sheath $(\mathrm{m})$ & $97.3^{*} 10^{-3}$ \\
\hline
\end{tabular} \begin{tabular}{|l|l|l|l|}
\hline Distance between phase $\mathrm{A}$ and $\mathrm{C}(\mathrm{m})$ & 0.54 & Sheath temperature coefficient & $4.03^{*} 10^{-3}$ \\
\hline
\end{tabular} Thickness of insulation $(\mathrm{m})$

Figure 1. Schematic diagram of a cross-bonded HV (CB) cable system

On-line, or in-service, PD monitoring (detection) is often carried out through high frequency current transformers (HFCT) being installed at cable joints or terminations. Advantages of using HFCTs are that they can be installed around the cable sheaths while the cable is in operation, which is not disruptive, and their presence does not add electrical stress to the cable system [7]. Decoupling PD through the cross-bonding link-lines would provide a safe alternative accessing PD signals from cable joints of $\mathrm{CB}$ cable systems. If successful the methodology opens a wider range of applications in $\mathrm{CB} \mathrm{HV}$ cable testing after installation, on service-aged and repaired cable systems [7]. In standard single core cables PD pulses travel within the core and the sheath, detecting the current pulse within the sheath indicates that a fault exists within the cable. The main challenge in PD monitoring of $\mathrm{CB} \mathrm{HV}$ cables lies in the interconnectedness of sheaths of the three phases. Pulses detected by a HFCT installed at a CB link-line will comprise of signals from the sheaths of all three phases, making it difficult to localise which of the three phases a PD signal has emanated from. A second challenge is the coupling effect when a PD pulse propagates in HV cable joints and $\mathrm{CB}$ link-lines, which made PD detection more complex. To address this issue the transmission characteristics, pulse attenuation and coupling effect of pulses propagating in joints and CB link-lines are studied in this paper. A model is also presented which describes pulse propagation in a CB cable system, imperative for PD monitoring and localisation. Finally, the paper presents a set of knowledge rules for $\mathrm{PD}$ monitoring and localisation in CB cable systems.

\section{THEORETICAL BACKGROUND}

\subsection{PULSE ATTENUATION IN CABLE}

A power cable, behaving as a transmission line to a travelling wave or signal, can be described by an equivalent circuit with distributed parameters per unit length, resistance $\mathrm{R}(\Omega / \mathrm{m})$, inductance $\mathrm{L}(\mathrm{H} / \mathrm{m})$, conductance $\mathrm{G}(\mathrm{S} / \mathrm{m})$, and capacitance $\mathrm{C}$ $(\mathrm{F} / \mathrm{m})$, as shown in Figure 2 [8].

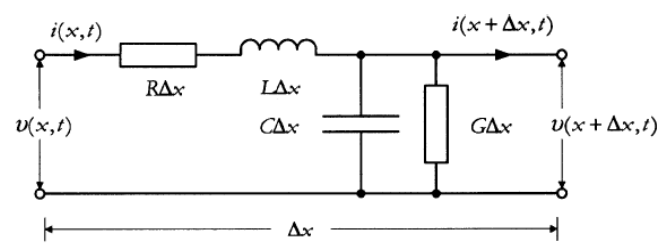

Figure 2. Equivalent circuit of a transmission line element of length $\Delta x$

Inductive and capacitive circuit parameters are frequency dependent, where frequency is given by $f(\mathrm{~Hz})$. The line is described by its propagation constant $\gamma$, with attenuation characteristic $\alpha(\mathrm{dB} / \mathrm{m})$ as real and phase characteristic $\beta(\mathrm{rad} / \mathrm{m})$ as the imaginary part. The following relation holds:

$$
\gamma(\omega)=\alpha(\omega)+j \beta(\omega)=\sqrt{(R+j \omega L)(G+j \omega C)}
$$

Where: $\omega=2 \pi f$ is angular velocity $(\mathrm{rad} / \mathrm{sec})$

As different frequencies of a pulse travel along a cable, they suffer different degrees of attenuation and delay. Attenuation $\alpha$ is due to losses in the solid dielectric and propagation through the resistance of the conductor, sheath and semi-conducting layers. Normally, attenuation severity increases with frequency. Dispersion, a phenomenon whereby signals of different frequency travel along a cable at different speeds, results in frequencydependent phase shifts. Attenuation and dispersion will, therefore, decrease the amplitude and increase the width of the pulse. The change in pulse width results in an increase in the pulse rise time as it propagates along a cable [9].

The propagation constant of a wave travelling along a transmission line of segment length $l$ is the complex ratio between the voltages of output (transmitted) pulse $\mathrm{V}_{\text {out }}$ and the input (incident) pulse $\mathrm{V}_{\text {in }}$ of the line segment. If a length of cable is considered as a linear system, this ratio represents the cable Transfer Function $\mathrm{H}_{\text {cable }}(\omega)$, as presented in equation (2):

$H_{\text {cable }}(\omega)=\frac{V_{\text {out }}}{V_{\text {in }}}=e^{-r(\omega) 2 l}=e^{-(\alpha(\omega)+j \beta(\omega)) 2 l}$

Although input and output pulses cannot be measured directly, due to existence of impedance mismatches in the system, a calibration procedure has been developed to obtain $\mathrm{H}_{\text {cable }}(\omega)$ [10]. The set-up and procedure can be discussed using Figure 3: line 1 is a $0.5 \mathrm{~m}$ length of $50 \mathrm{ohm}$ co-axial cable connecting the pulse generator to an oscilloscope, line 2 is a $20 \mathrm{~m}$ length of the co-axial cable connecting the pulse generator to the cable under test. Initially line 2 is short-circuited and the measured signal from this configuration is recorded as $\mathrm{V}_{-3}$ short, thereafter the device under test (DUT) is connected to line 2 and data collected. $\mathrm{V}_{-3}{ }^{\mathrm{m}}$ is the signal due to impedance mismatch between line 2 and DUT, $\mathrm{V}_{-3}$ is the signal detected due to DUT. The cable transfer function can be obtained from:

$H_{\text {cable }}(\omega)=e^{-r(\omega) 2 l}=\frac{V_{-3} V_{-3}^{\text {short }}}{\left(V_{-3}^{m}\right)^{2}-\left(V_{-3}^{\text {short }}\right)^{2}}$

Where $\mathrm{V}_{-3}, \mathrm{~V}_{-3}{ }^{\text {short }}$ and $\mathrm{V}_{-3}{ }^{\mathrm{m}}$ are as described above. 


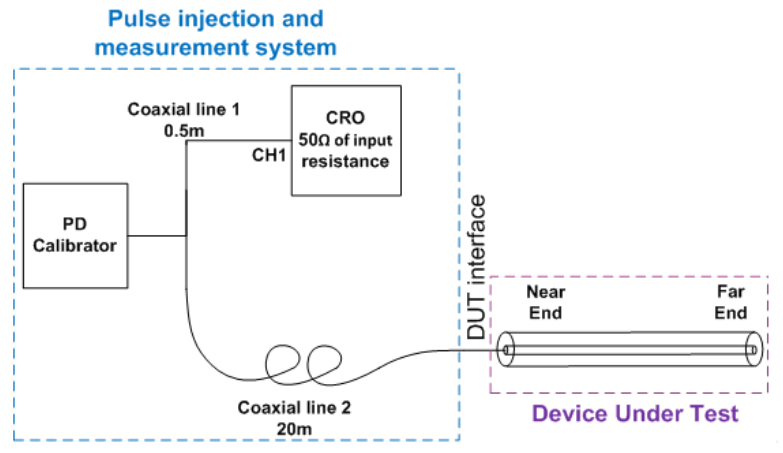

Figure 3. Schematic drawing of the calibration procedure setup

Attenuation and phase characteristics can be determined from (3) as

$$
\begin{aligned}
& \alpha(\omega)=-\frac{1}{2 l} \ln \left|H_{\text {cable }}(\omega)\right| \\
& \beta(\omega)=-\frac{1}{2 l} \angle H_{\text {cable }}(\omega)
\end{aligned}
$$

Following the calibration procedure, an experiment was carried out by injecting a calibration pulse, shown in Figure 4, into a $38.8 \mathrm{~m}$ length of $11 \mathrm{kV}$ single core Ethylene-Propylene-Rubber (EPR) insulated cable. The pulse generator was designed and constructed to produce signals, such as those in Figure 4, which mimicked PD signals recorded on practical cable systems. The attenuation and phase characteristics obtained from the transfer function of the EPR cable are given in Figures 5(a) and 5(b) respectively.

Results shown in Figure 5 indicate that the cable behaves like a transmission line up to a frequency of $80 \mathrm{MHz}$, beyond this the characteristics becomes complicated and the cable cannot be represented using the transfer function as described previously.

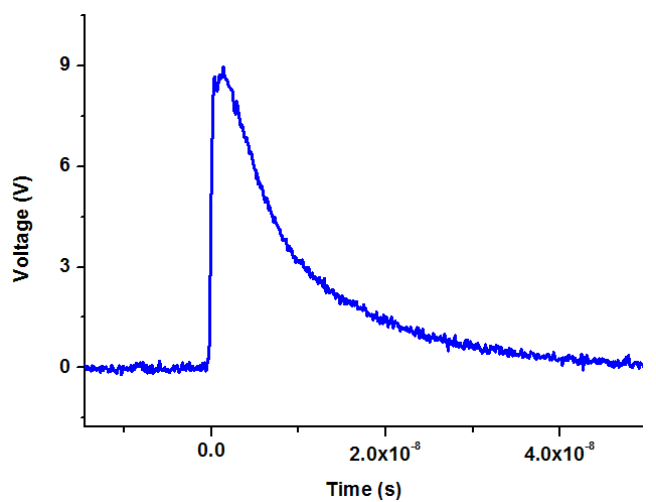

Figure 4. The injected pulse

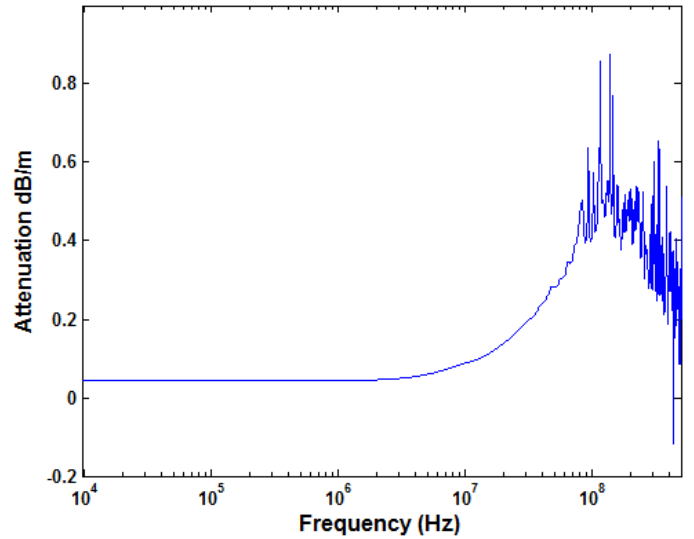

(a) Attenuation characteristic

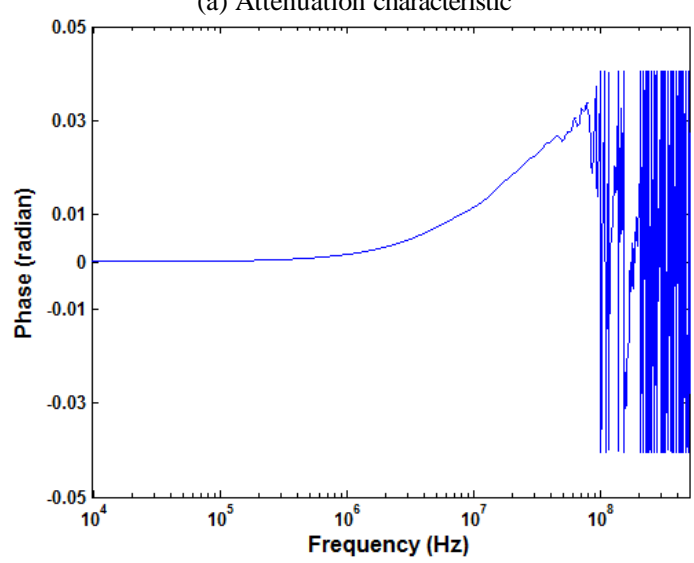

(b) Phase characteristic

Figure 5. Measured results of attenuation and phase characteristics of an $11 \mathrm{kV}$ EPR insulated cable

\subsection{THE COUPLING EFFECT OF PULSE PROPAGATION}

To investigate the coupling effect when a pulse propagates in $\mathrm{HV}$ cable joints and CB link-lines (MV cable), a series of different test arrangements were developed. In all cases, $50 \Omega$ signal coaxial cables were used in the laboratory investigation due to unavailability of real-world cables of reasonable lengths. Due to the similarity in cable construction, the pulse coupling principle in coaxial cable and power cable are the same.

The initial test set-up, as shown in Figure 6(a), was constructed to investigate the relationship between the detected pulse from HFCTs clipped around the CB link-line and the detected pulses travelling along the centre conductor and sheath of cable.

Figure 6(b) shows that when two pulses individually propagate along the conductor and sheath of a coaxial cable, the measured pulse detected by a CT clipped around the cable is the resultant sum of the two pulses. 


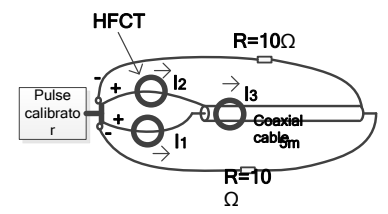

(a) The test set-up

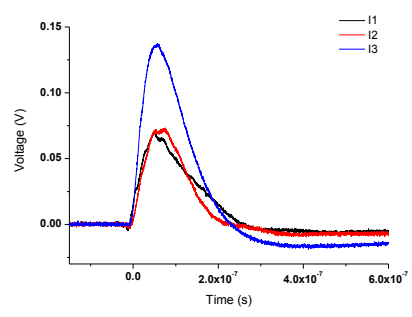

(b) Measurement results
Figure 6. Test set-up for investigation of pulses through the CB link-line.

When a PD occurs within the main insulation of a cable section, it results in charge concentration in the region of the central conductor and the sheath closest to the PD activity. This charge then generates, along both cable conductor and the sheath, two pulses of the same amplitude traveling in opposite directions towards the cable terminals [11] (Not listed). In CB HV cable systems, a current pulse in the center conductor propagating through a cable joint and the connected CB link-line will continue into the centre conductor of next cable section, a current pulse in the cable sheath will travel through either the center conductor or sheath of a CB link-line to a second cable's sheath circuit.

To investigate the coupling effect two experimental set-ups were developed: these are shown in Figure 7. In Figure 7(a) the sheath of the coaxial cable is connected to the pulse generator as shown; the cable center conductor connects at one end (end A) to a $15 \mathrm{~m}$ copper wire and the other end (end B) is open-circuited. In Figure 7(b) the center conductor is connected to the pulse generator as shown; end $\mathrm{A}$ of the cable sheath is connected to a $15 \mathrm{~m}$ copper wire and end B of the cable sheath is open-circuited. In both the tests, the length of the coaxial cable was $20 \mathrm{~m}$ and the pulse applied is shown in Figure 8. (Why a different pulse from Figure 4?) Three HFCTs, placed $0.1 \mathrm{~m}$ away from end A as shown, are connected to an oscilloscope with a sampling rate of $5 \mathrm{GS} / \mathrm{s}$, a bandwidth of $500 \mathrm{MHz}$ and vertical resolution of 9 bits. The expected current direction in the cable through each HFCT is indicated by the arrow.

Due to the very short distances involved, Figures 9(a) and 9(b) demonstrate that the difference in time of arrival of the pulses at all three HFCTs is insignificant. The detected current pulse signals satisfy equation (6) below, indicating that when a pulse propagates into one cable conductor, signals are generated and propagate in the other conductor as a result of the coupling effect.

$$
I_{3}=I_{1}-I_{2}
$$

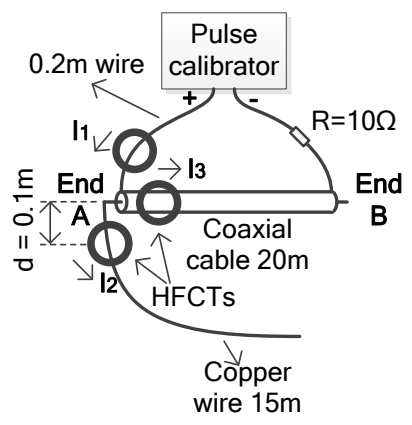

(a) Set-up 1

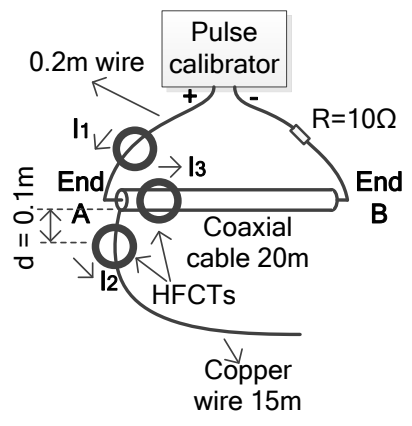

(b) Set-up 2
Figure 7. Experimental arrangements for pulse propagation study
In order to confirm the polarity and propagation direction of the coupling pulses, which allowed the calculation in equation 6 to be completed, two further experiments were completed. These are the same as those described in Figure 7 except that the HFCT on the $15 \mathrm{~m}$ copper wire was $9.9 \mathrm{~m}$ away from End A of the cable. Figure 10 demonstrates that current pulse $\mathrm{I}_{2}$, from the HFCT on the $15 \mathrm{~m}$ copper wire, is delayed by $33 \mathrm{~ns}$ when compared with the other two pulses, i.e. the expected pulse propagation time through $9.9 \mathrm{~m}$ of copper wire $\left(9.9 \mathrm{~m} / 3 * 10^{8} \mathrm{~m} / \mathrm{s}=33 \mathrm{~ns}\right)$.

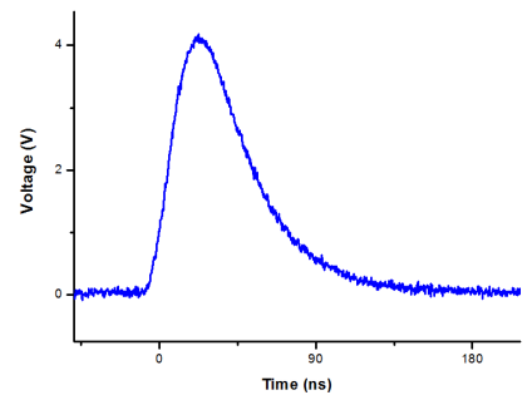

Figure 8. Pulse generated by pulse calibrator

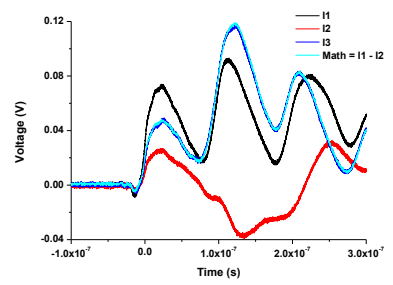

(a) Result of set-up 1

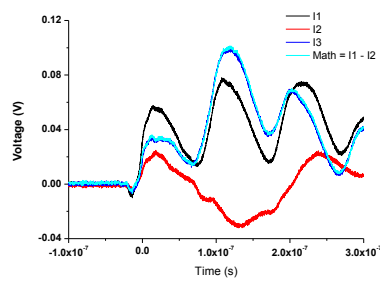

(b) Result of set-up 2
Figure 9. Comparison of pulse magnitudes with $\mathrm{d}=0.1 \mathrm{~m}$
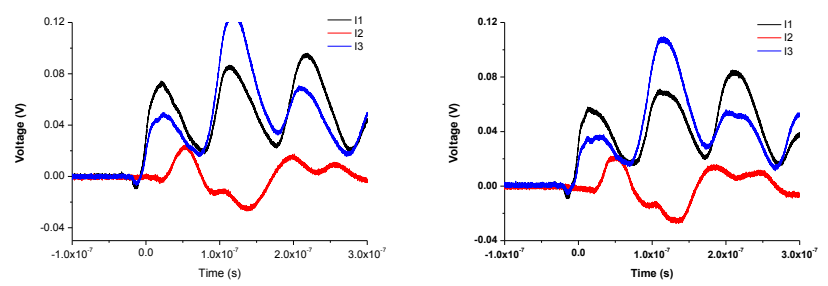

(a) Result of set-up 1 (b) Result of set-up 2

Figure 10. Comparison of pulse magnitudes with $d=9.9 \mathrm{~m}$

It can, therefore, be concluded that when a positive pulse $\mathrm{I}_{1}$ propagates into one end of a cable sheath, a coupling event causes charge to be developed in the center conductor. From this charge, two pulses are generated which propagate in opposite directions in the cable center conductor (in Figure 11a). The two coupled pulses $\left(\mathrm{I}_{2}{ }^{\prime}\right.$ and $\left.\mathrm{I}_{2}\right)$ have the same shape, same amplitude but, unexpectedly, opposite polarities. This statement is justified as follows: to obtain the current pulse magnitudes in Figures 9(a) and 9 (b) the current in the coaxial cable, $I_{3}$, was obtained by subtracting $\mathrm{I}_{2}$ from $\mathrm{I}_{1}$; this indicates that the current, $\mathrm{I}_{3}$ must come from a positive current pulse, $I_{1}$, and a negative current pulse $I_{2}$; as shown in Figures 11(a) and 11(b). A similar argument can be used for an injected pulse of the opposite polarity.

The coupling efficiency where the pulse is injected into the sheath, set-up 1 , is defined as $\mathrm{k}_{\mathrm{S}}\left(\mathrm{k}_{\mathrm{s}}=\left|\mathrm{I}_{2} / \mathrm{I}_{1}\right|\right)$. Similarly the coupling efficiency in set-up 2 , where the pulse is injected into the center conductor, is defined as $\mathrm{k}_{\mathrm{C}}\left(\mathrm{k}_{\mathrm{c}}=|\mathrm{I}| / 2 / \mathrm{I}_{1} \mid\right)$. It is noted that the value of $\mathrm{k}_{\mathrm{C}}$ is a little greater than $\mathrm{k}_{\mathrm{S}}$. 

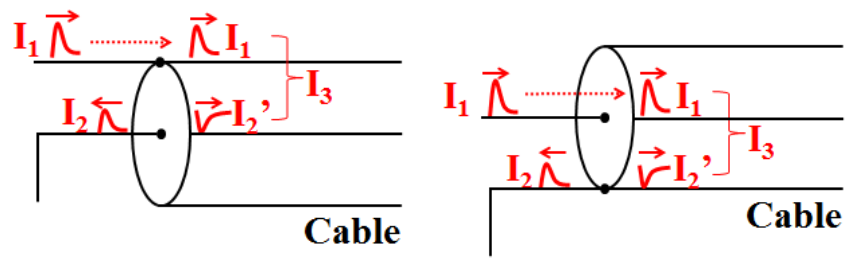

(a) A pulse travels into the sheath (b) A pulse travels into the centre conductor Figure 11. Positive pulse propagation into a cable

\section{PULSE PROPAGATION IN CB HV CABLE SYSTEMS}

\subsection{PD MONITORING IN HV CB CABLE SYSTEM}

PD sensors can be installed at the major intersections or terminations of a CB HV cable system. For an example system, as shown in Figure 12, there are four possible sites, numbered 1 to 4. To obtain a low-cost solution, the optimal method for installation of PD sensors to monitor and localize PD pulses would be to install 6 sensors in the two sets of joints at (2) and (3).

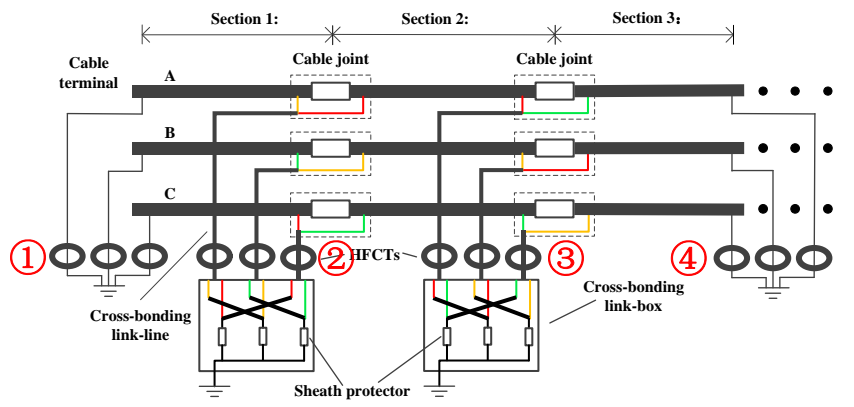

Figure 12. Proposed sensor installation for on-line $\mathrm{PD}$ monitoring in a $\mathrm{CB}$ HV cable system

\subsection{PULSE PROPGATION IN HV CB CABLE SYSTEM}

The parameters of a $\mathrm{CB}$ cable system are dependent on the physical size of $\mathrm{HV}$ cables and CB link-lines, earth resistance, etc. A model has been developed to analyze PD propagation in a CB HV cable system according to a practical system in Wuhan, China, see Figure 13. The cable model has two CB link-boxes; each connects three $\mathrm{CB}$ link-lines (MV cables). The sheath of Phase A section 1 connects through the center conductor of a CB link-line to link-box 1, at link-box 1 the sheath of Phase B section 2 is connected to it via the sheath of a CB link-line. Similar connectivity can be shown for the other Phase sheaths.

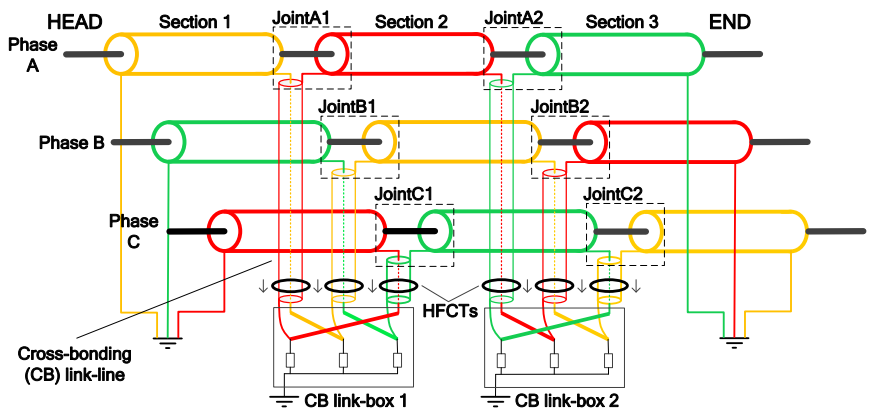

Figure 13. Model of a Wuhan CB HV cable system
Using the model a study has been undertaken to investigate the effect of PD signals emanating from four sites of origin. Three of the sites for PD pulses are the three sections of phase A, the fourth is taken as being in joint A1. Following the earlier discussion, the PD pulses at the site of origin are all assumed to produce positive pulses travelling in opposite direction along the center conductor, $I_{1}$ in Figure 14, while negative pulses travel in opposite direction along the $\mathrm{HV}$ cable sheath, - $\mathrm{I}_{1}$ in Figure 14. The characteristics obtained in the preceding section of the paper are applied to analyze the pulse propagation in CB cable systems.

\subsubsection{PD from section 1 of phase $A$}

The first case is a PD source in section 1 of phase A, assumed to be $l_{1}$ metres away from joint $\mathrm{A} 1$, as shown in Figure 14 . Components of the original PD pulses, $\pm \mathrm{I}_{1}$, propagate along the cable to joint A1 (Figure 14), CB link-lines and CB linkbox (Figure 15). The resultant pulses are detected by HFCTs at phase $\mathrm{A}, \mathrm{B}, \mathrm{C}$ of the $\mathrm{CB}$ link-lines. Equations relating to pulse propagation are given in (8)-(13):

$I_{2}=I_{1} e^{-\gamma_{1} l_{1}}$

$I_{3}=k_{h c} I_{2}$

$I_{4}=-k_{m c} I_{2}$

$I_{5}=k_{m s} I_{3}$

$I_{6}=I_{3}-I_{4}$

$I_{7}=-I_{5}-I_{2}$

Where $I_{1}$ is the component of the original PD current pulse at the source, $\gamma_{1}$ is the propagation constant of the HV cables, $\mathrm{k}_{\mathrm{hc}}$ is the coupling coefficient of $\mathrm{HV}$ cables, $\mathrm{k}_{\mathrm{mc}}$ and $\mathrm{k}_{\mathrm{ms}}$ are the coupling coefficient of CB link-lines (MV cables).

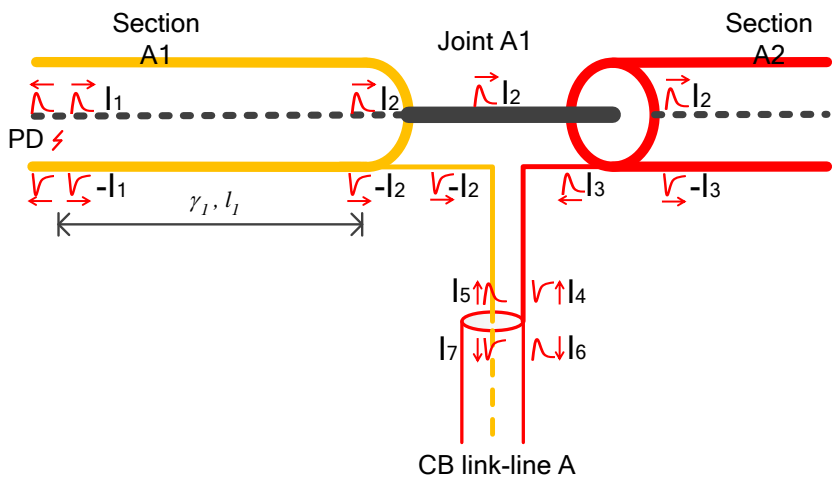

Figure 14. Coupling effect of a PD pulse propagating through a cable joint

The equations relating to propagation in the CG links, Figure 15, are given in equations (14)-(19):

$$
\begin{aligned}
& I_{8}=I_{7} e^{-\gamma_{2} l_{2}} \\
& I_{9}=I_{6} e^{-\gamma_{2} l_{2}} \\
& I_{10}=-k_{m s} I_{8}+k_{m c} I_{9} \\
& I_{11}=I_{8}-k_{m c}^{2} I_{9} \\
& I_{12}=-k_{m s}^{2} I_{8}+I_{9} \\
& I_{13}=k_{m s} I_{8}-k_{m c} I_{9}
\end{aligned}
$$


Where $\gamma_{2}$ is the propagation constant of the CB link-lines and $l_{2}$ is the length of the CB link-line which connects to joint A1.

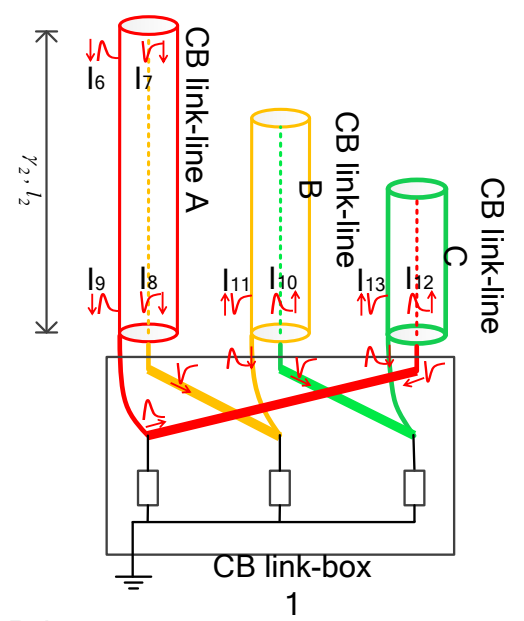

Figure 15. A PD pulse propagating through a CB cable system

As the HFCTs are installed around the CB link-lines close to CB link-box and the positive direction of HFCTs points from $\mathrm{CB}$ link-lines to CB link-box, the pulses detected are given by:

$$
\begin{aligned}
& I_{H F C T 1 A}=I_{8}+I_{9} \\
& I_{H F C T 1 B}=-I_{10}-I_{11} \\
& I_{H F C T 1 C}=-I_{12}-I_{13}
\end{aligned}
$$

Using equation (8)-(19), it can be shown that

$$
\begin{aligned}
I_{H F C T I A}= & \left(k_{h c}+k_{m c}-k_{m s} k_{h c}-1\right) I_{1} e^{-\gamma_{1} l_{1}} e^{-\gamma_{2} l_{2}} \\
I_{H F C T I B}= & {\left[\left(1-k_{m s}\right)\left(k_{m s} k_{h c}+1\right)+\right.} \\
& \left.\left(k_{m c}^{2}-k_{m c}\right)\left(k_{h c}+k_{m c}\right)\right] I_{1} e^{-\gamma_{1} l_{1}} e^{-\gamma_{2} l_{2}} \\
I_{H F C T I C}= & {\left[\left(k_{m s}-k_{m s}^{2}\right)\left(k_{m s} k_{h c}+1\right)+\right.} \\
& \left.\left(k_{m c}-1\right)\left(k_{h c}+k_{m c}\right)\right] I_{1} e^{-\gamma_{1} l_{1}} e^{-\gamma_{2} l_{2}}
\end{aligned}
$$

For simplicity it is assumed that $\mathrm{k}_{\mathrm{mc}}=\mathrm{k}_{\mathrm{hc}}=\mathrm{k}_{\mathrm{c}}, \mathrm{k}_{\mathrm{ms}}=\mathrm{k}_{\mathrm{s}}$, using values obtained from Section 2.2, then

$$
I_{H F C T 1 A}: I_{H F C T 1 B}: I_{H F C T 1 C}=-0.378: 0.567:-0.215
$$

The relationship between the magnitudes and polarities of three pulses detected by HFCTs close to CB link-box 1 is shown in Figure 16. This indicates that, as a result of an initial PD pulse in Phase A, the signal detected in phase B has largest magnitude pulses (almost twice that in Phases A and C). The $\mathrm{PD}$ pulse in Phase $\mathrm{B}$ has positive polarity, while pulses detected in phase $\mathrm{A}$ and $\mathrm{C}$ both have a negative polarity.

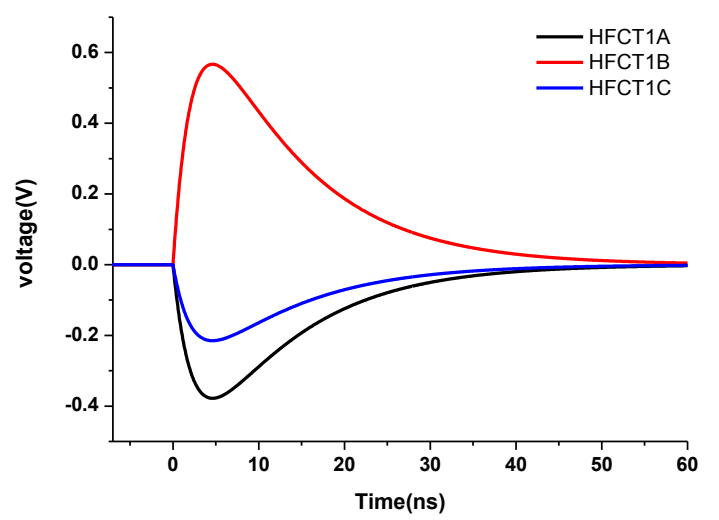

Figure 16. PD in section A1 with HFCTs close to CB link-box 1

\subsubsection{PD from section 2 of phase A}

Using the principle shown above, the propagation of PD from section 2 of phase $A$ is studied. The results of the pulses detected by HFCTs close to CB link box 1 and CB link box 2 are given in equation (27)-(28) and Figures 17 and 18.

In Figure 17, at CB link-box 1, the signal detected in Phase $\mathrm{C}$ has the largest magnitude, Phase $\mathrm{A}$ (where the pulse originated) is lower and $\mathrm{B}$ is lowest. Phase $\mathrm{C}$ has positive polarity, pulses detected in both phase $\mathrm{A}$ and $\mathrm{B}$ are negative polarity. Comparison of the data relating to a $\mathrm{PD}$ in section 1 of Phase A, Section 3.2.1 and equation (26) and Figure 16, with that of equation (28) and Figure 18 demonstrates that the three pulses at CB link-box 2 are the same.

$$
\begin{aligned}
& I_{H F C T 1 A}: I_{H F C T 1 B}: I_{H F C T 1 C}=-0.424:-0.204: 0.552 \\
& I_{H F C T 2 A}: I_{H F C T 2 B}: I_{H F C T 2 C}=-0.378: 0.567:-0.215
\end{aligned}
$$

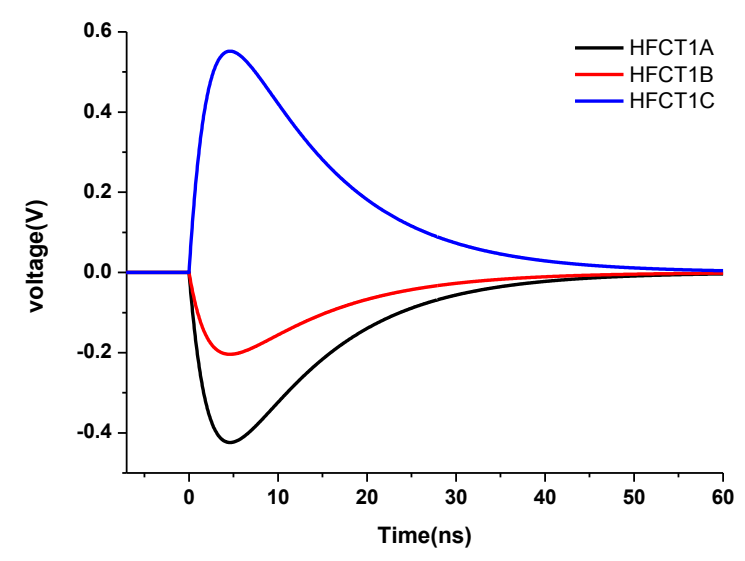

Figure 17. PD in section $\mathrm{A} 2$ with HFCTs close to $\mathrm{CB}$ link-box 1 


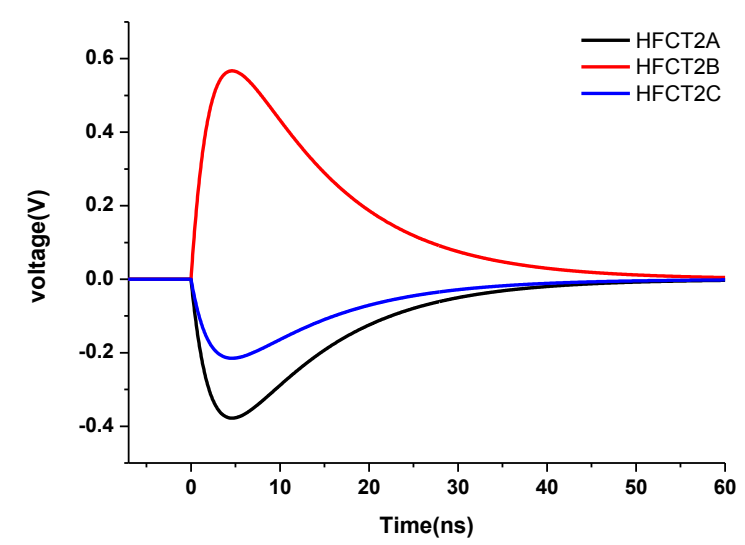

Figure 18. PD in section $\mathrm{A} 2$ with HFCTs close to $\mathrm{CB}$ link-box 2

\subsubsection{PD from section 3 of phase A}

Appling the similar procedure to develop the effect of PD from section 3 of phase A, the results of the pulses detected by HFCTs close to CB link box 2 are given in equation (29) and Figure 19.

From Figure 19 and equation (29) it can be seen that the three pulses at CB link-box 2 are the same as those at CB link-box 1 in section 3.2.2.

$$
I_{H F C T 2 A}: I_{H F C T 2 B}: I_{H F C T 2 C}=-0.424:-0.204: 0.552
$$

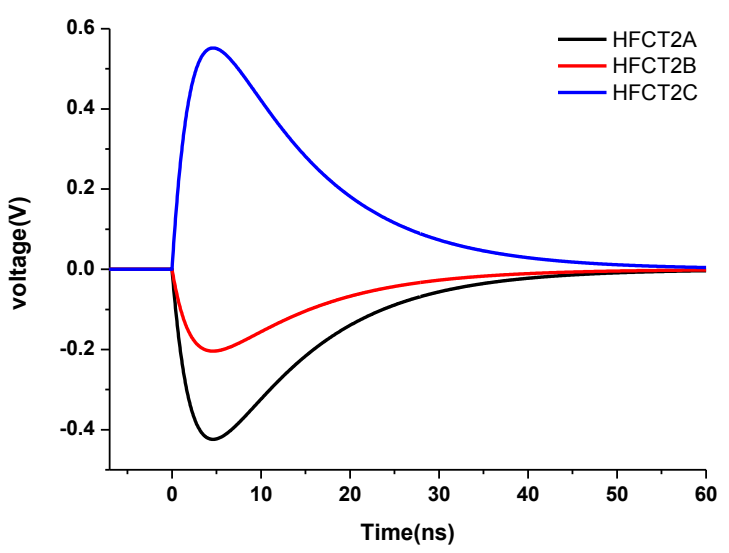

Figure 19. PD in section A3 with HFCTs close to CB link-box 2

\subsubsection{PD in joint A1}

Appling the similar procedure to develop the effect of PD from joint $\mathrm{A} 1$, and the results of the pulses detected by HFCTs close to CB link box 1 are given in equation (30) and Figure 20.

From Figure 20, the signal detected in phase A at CB linkbox 1 has the opposite polarity to that of the other phases, and the amplitude is about twice that of the others.

$$
I_{H F C T 2 A}: I_{H F C T 2 B}: I_{H F C T 2 C}=-1.283: 0.579: 0.539
$$

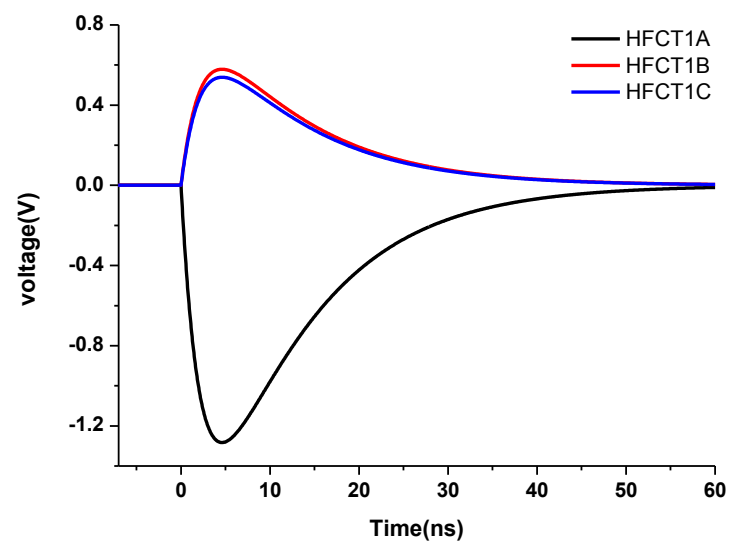

Figure 20. PD in joint A1 with HFCTs close to CB link-box 1

\section{KNOWLEDGE RULES FOR PD LOCALISATION IN CROSS-BONDED CABLE SYSTEMS}

According to the simulation results of pulse propagation in $\mathrm{CB}$ HV cable systems in Section 3, PD sources emanating from different locations manifest different characteristics of pulse magnitude and polarity when detected by the HFCTs installed at $\mathrm{CB}$ link-lines close to the two $\mathrm{CB}$ link-boxes. This knowledge can be used for PD monitoring and localization in $\mathrm{CB}$ cable systems. The procedure can be used to determine the optimal method for PD sensor installation in other, more complex systems. PD localization in HV CB cable systems includes two steps.

The first step is to obtain knowledge rules to determine from which phase and section of the $\mathrm{CB}$ cable system a PD source emanated from. Using the Wuhan CB system as an example, the knowledge rules given in Table 1 indicate that different PD sources have unique relationships with the polarity and magnitude of the pulses detected by the 6 HFCTs in a major cable section.

Table 1. Knowledge rules to locate the phase and section of PD source

\begin{tabular}{l|ccc|ccc}
\hline \multirow{2}{*}{ PD source in } & \multicolumn{4}{|c|}{ HFCTs at CB link-box 1 } & \multicolumn{4}{|c}{ HFCTs at CB link-box 2 } \\
\cline { 2 - 7 } & A & B & C & A & B & C \\
\hline Section A1 & -2 & +1 & -3 & & & \\
Section A2 & -2 & -3 & +1 & -2 & +1 & -3 \\
Section A3 & & & & -2 & -3 & +1 \\
Section B1 & -3 & -2 & +1 & & & \\
Section B2 & +1 & -2 & -3 & -3 & -2 & +1 \\
Section B3 & & & & +1 & -2 & -3 \\
Section C1 & +1 & -3 & -2 & & & \\
Section C2 & -3 & +1 & -2 & +1 & -3 & -2 \\
Section C3 & & & & -3 & +1 & -2 \\
Joint A1 & -1 & +2 & +2 & & & \\
Joint A2 & & & & -1 & +2 & +2 \\
Joint B1 & +2 & -1 & +2 & & & +2 \\
Joint B2 & & & & +2 & -1 & +2 \\
Joint C1 & +2 & +2 & -1 & & & \\
Joint C2 & & & & +2 & +2 & -1 \\
\hline
\end{tabular}

Where "+" and "-" represents positive and negative polarity respectively; numbers of " $1,2,3$ " represent the relative level of PD pulse magnitude, " 1 " is the greatest, " 2 " is the middle and " 3 " the smallest. 
This Table presumes that the PD pulses at the site of origin are positive pulses travelling along the center conductor of the cable while negative pulses travel along HV cable sheath. If the PD pulses at the site of origin are assumed to be negative pulses travelling in the center conductor and positive pulses in the cable sheath, only the polarity of the results above will reverse, the magnitude relationships will remain the same.

The second step is to determine the distance between the PD source and the position where a HFCT is installed. This can be carried out using the Rise Time Transfer Function (RTTF) method for PD localization in a single phase cable.

\section{CONCLUSION}

Online PD monitoring in CB HV cable systems is usually carried out through HFCTs being installed at cable joints or terminations where HFCTs can be clipped around CB link-lines. Due to the interconnectedness of sheaths of the three phases, PD pulses detected by a HFCT comprise signals from the sheaths of three phases. The complex coupling effects, when pulses propagate in $\mathrm{HV}$ cable joints and CB link-lines, make it difficult to localize which of the three phases a PD signal has emanated from. This paper studied the propagation characteristics, pulse attenuation and coupling effects of pulses propagating in cables by laboratory experiments.

A model, based on a practical $\mathrm{CB}$ cable system, has been developed to analyze PD pulse propagation in a CB cable system. The study applies the propagation characteristics gained from the laboratory work to demonstrate how understanding of signal propagation in $\mathrm{CB}$ system can be used to identify sites of origin of PD. Based on the study, the optimal method for PD sensor installation to monitor and localize PD pulses in $\mathrm{CB}$ systems is proposed, i.e. to install HFCT sensors round the $\mathrm{CB}$ link-lines close to the $\mathrm{CB}$ link-boxes. In addition, knowledge rules to locate the phase and section of a PD source in CB cable systems are obtained as different PD source locations have unique relationships with the polarities and magnitudes of the pulses detected by HFCTs.

\section{REFERENCES}

[1] C. Zhou et al, 2012, "Statistical approaches for analysis of condition monitoring and failure data in power cables", CIGRE D1-314, Paris.

[2] Fukunaga, K. 1992, "New partial discharge detection method for live UHV/EHV cable joints", Electrical Insulation, IEEE Transactions on, Volume: 27, Issue: 3, 669 - 674.

[3] Mansor, M. 2002, "Classification of PD patterns in XLPE cables under various soil conditions using statistical technique", Conference Record of the 2002 IEEE Int'1 Sym on Electrical Insulation, USA.

[4] S. Boggs and J. Densley, 2000, "Fundamentals of Partial Discharge in the Context of Field Cable Testing", Electrical Insulation, IEEE Transactions on, Vol. 16, No. 5, pp.13-18.

[5] Okubo, H. et al, 2005. "A novel technique for partial discharge and breakdown investigation based on current pulse waveform analysis", Dielectrics and Electrical Insulation, IEEE Transactions on, Volume: 12, Issue: $4,736-744$.

[6] IEEE Std. 575-1988, "IEEE guide for the application of sheath-bonding methods for single-conductor cables and the calculation of induced voltages and currents in cable sheaths".

[7] Weissenberg, W. et al, 2004, "On-site PD detection at cross-bonding links of HV cables", CIGRE, Sessions, Paris, Paper B1-102.
[8] Papazyan, R., Pettersson, P., Edin, H., Eriksson, R., Gafvert, U., "Extraction of high frequency power cable characteristics from Sparameter measurements", Dielectrics and Electrical Insulation, IEEE Transactions on, Volume: 11, Issue: 3, Page(s): 461 - 470, 2004.

[9] Cavallini, A., Montanari, G.C., Puletti, F., "A novel method to locate PD in polymeric cable systems based on amplitude-frequency (AF) map", Dielectrics and Electrical Insulation, IEEE Transactions on, Volume: 14 , Issue: 3, Page(s): 726 - 734, 2007.

[10] Papazyan, R., Eriksson, R., "Calibration for time domain propagation constant measurements on power cables", Instrumentation and Measurement, IEEE Transactions on, Volume: 52 , Issue: 2, Page(s): $415-418,2003$.

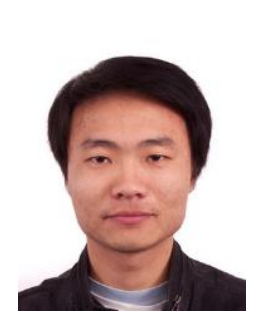

Bojie Sheng (M'13) was born in China. He received his B.Sc. degree from School of Electrical Engineering, Wuhan University, China in 2008. He is now a PhD candidate in School of Electrical Engineering, Wuhan University and his research is mainly focused on the diagnostic methodology for power cable insulation as well as lightning protection for microelectronic equipment.

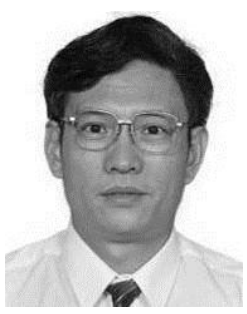

Wenjun Zhou (M'90-SM'00) received the Ph.D. degree from Wuhan Conservancy and Electric Power Institute, China, in 1990. Currently, he is a professor in Wuhan University, China. He is a member of High Voltage Committee of Chinese Society for Electrical Engineering, a member of Electro-technical Test and Measurement Committee of China Electro-technical Society, a member of China Lightning Protection Standard Committee. He is also the vice director of Hubei High Voltage Committee. His areas of research interest include lightning protection for microelectronic equipment as well as the diagnostic methodology for outdoor electrical insulations.

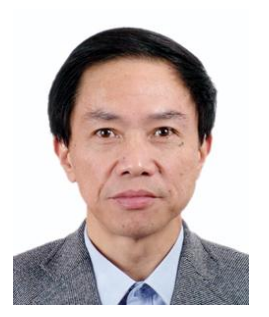

Jianhui Yu was born in China. He received the M.Sc. degree in high voltage and electrical insulation from Wuhan University, Wuhan, China. Currently, he is a Professor in the School of Electrical Engineering, Wuhan University. Prof. $\mathrm{Yu}$ is a member of the National Committees for Live-Wire Work Standard and the China Group for IEC/TC78. His research mainly focuses on high voltage and electrical insulations.

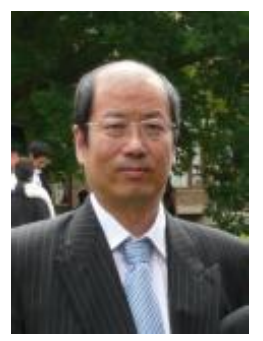

Chengke Zhou (M'06, SM'13) received the B.Sc. and M.Sc. degrees in electrical engineering from HuaZhong University of Science and Technology, China in 1983 and 1986, respectively, and the Ph.D. degree at the University of Manchester U.K., in 1994. Since then, he worked in Glasgow Caledonian University (GCU), as a Lecturer and Senior Lecturer, and in Heriot-Watt University as a Reader. In 2007 he returned to GCU as a Professor. He has published more than 100 papers in the area of PD based condition monitoring of $\mathrm{MV} / \mathrm{HV}$ plant and power system analysis. He is a Senior member of IEEE and Fellow of IET.

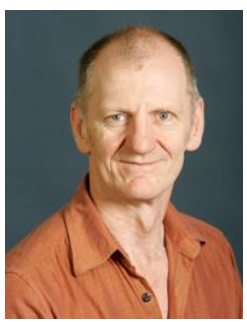

Donald M. Hepburn (M'08) received his B.A. (Hons) from the Open University in 1987and Ph.D. degree from Glasgow Caledonian University (GCU) in 1994. $\mathrm{He}$ is a Senior Lecturer at GCU, a member of the IEEE, Institute of Physics, the IET and C.Eng. He has 20 years of industrial research experience and has been involved in research into HV insulation systems at GCU for over 20 years. His research interests cover monitoring physical and chemical change in HV/MV insulation materials and application of advanced digital signal processing to information from electrical, acoustic and RF monitoring techniques. 